\title{
Eficiência fotoquímica e produtividade de frutos de meloeiro cultivado sob diferentes lâminas de irrigação
}

\section{Photochemical efficiency and yield of melon plants cultivated under different irrigation levels}

\author{
Janivan Fernandes Suassuna ${ }^{1}$; Alberto Soares de Melo ${ }^{2 *}$; Flávio Silva Costa ${ }^{1}$; \\ Pedro Dantas Fernandes ${ }^{3}$; Rosinaldo Sousa Ferreira ${ }^{4}$; Mônica Shirley da \\ Silva Sousa ${ }^{4}$
}

\section{Resumo}

O meloeiro tem reconhecida importância sócio-econômica no Nordeste do Brasil, porém a falta ou excesso de água limita o seu cultivo. Para tanto, é necessário determinar a quantidade ideal para a obtenção do máximo rendimento. Assim, objetivou-se avaliar a eficiência fotoquímica e o rendimento do meloeiro Cantaloupe sob diferentes lâminas de irrigação. $O$ trabalho foi conduzido em condições de campo, adotando-se o delineamento em blocos ao acaso com 4 tratamentos $[(60 ; 80 ; 100$ e $120 \%$ da ETo $\left(\mathrm{mm} \mathrm{dia}^{-1}\right)$ ] que corresponderam aos volumes de água acumulados de 1250, 1680, 2110 e $2540 \mathrm{~m}^{3}$ ciclo $^{-1}$, respectivamente; e 6 repetições com 10 plantas úteis por parcela. Analisaram-se as variáveis: fluorescência da clorofila a, rendimento e atributos físico-químicos dos frutos. A lâmina de água de $80 \%$ da ETo promoveu maior eficiência do fotossistema II. Houve menor produção de frutos da Classe I na lâmina superior a $100 \%$ da ETo; a incidência de frutos das Classes II e III cresceu linearmente com o aumento das lâminas de água. O tamanho dos frutos foi reduzido com irrigações superiores a $100 \%$ da ETo; no entanto, o teor de açúcar foi satisfatório até irrigações com $80 \%$ da ETo. Lâminas de água baseadas em $100 \%$ da ETo proporcionam os melhores índices fisiológicos e incrementos nas variáveis de produção.

Palavras-chave: Cucumis melo cantaloupensis Naud., lâminas de água, fluorescência da clorofila $a$, produção de frutos

\begin{abstract}
The melon crop has great social and economic importance to Northeastern Brazil, however, lack and excess of water affect growth. Therefore it is necessary to determine ideal water amount to obtain the maximum yield. This research work aimed to evaluate photochemical efficiency and yield of Cantaloupe melon under different irrigations levels. The work was carried in field conditions, adopting a randomized block design with 4 treatments $\left[\left(60,80,100\right.\right.$, and $120 \%$ of ET0 $\left(\mathrm{mm} \mathrm{day}^{-1}\right)$ corresponded to the volume of water accumulated during the cycle: 1250, 1680, 2110 and $2540 \mathrm{~m}^{3}$ cycle $^{-1}$, respectively, and 6 replications with 10 plants per experimental unit. The following variables were analyzed: chlorophyll fluorescence, yield and physical and chemical attributes fruits. The $80 \%$ ETo water level provided the higher efficiency
\end{abstract}

\footnotetext{
1 Pós-graduandos do curso de Doutorado em Engenharia Agrícola da Universidade Federal de Campina Grande, UFCG. Av. Aprígio Veloso, 882, Bodocongó, CEP 58.429-140, Campina Grande, PB. E-mail: jf.su@hotmail.com; flaviocostapb@yahoo. com.br

2 Prof. do Dept ${ }^{\circ}$ de Agrárias e Exatas da Universidade Estadual da Paraíba, UEPB. CEP 58884-000, Catolé do Rocha, PB. E-mail: alberto@uepb.edu.br

3 Prof. da Universidade Federal de Campina Grande, UFCG. E-mail: pdantas@pq.cnpq.br

4 Pós-graduandos do curso de Mestrado em Engenharia Agrícola da Universidade Federal de Campina Grande, UFCG. E-mail: rosinaldoagrarias@hotmail.com; moni_shiley@hotmail.com

* Autor para correspondência 
of Photosystem II. There was lower production of Class I fruits with the level irrigation higher than $100 \%$ ETo; and the incidence of the class II and III fruits increased linearly with increasing water levels. There was a reduction in fruit size with irrigation higher than $100 \%$ ETo, however the sugar content was satisfactory with irrigation up to $80 \%$ ETo. Water levels based on $100 \%$ ETo provide the best physiological indices and increasing in production variables.

Key words: Cucumis melo cantaloupensis Naud., water levels, chlorophyll fluorescence, fruits production

\section{Introdução}

Pertencente à família das Cucurbitáceas, o meloeiro (Cucumis melo L.) é uma hortaliça muito consumida e de grande popularidade no mundo, com reconhecida importância econômica e social, principalmente nas regiões tropicais, sendo a oitava hortaliça de fruto mais produzida e presente entre as dez mais exportadas no mercado internacional, com estimativa em mais de 1,6 milhões de toneladas por ano (SOUSA et al., 2010).

No Brasil, a produção de melão em 2009, foi cerca de 400 mil toneladas de frutos (IBGE, 2010), apresentando fortes tendências de crescimento em função do consumo interno e das exportações. No cenário nacional, o Nordeste participa com mais de 90\%, destacando-se os estados do Rio Grande do Norte, Ceará, Pernambuco e Bahia (AGRIANUAL, 2009), onde o Rio grande do Norte é o maior produtor e possui a maior área cultivada (FERREIRA; TORRES; COSTA, 2007; DEMARTELAERE et al., 2009).

Dentre os fatores que podem afetar produtividade e qualidade de frutos de meloeiro, citam-se com frequência, as condições hídricas do solo. A falta ou o excesso hídrico afeta o crescimento, a sanidade e a produção das plantas (KOETZ et al., 2006; DOGAN et al., 2008; SIQUEIRA et al., 2009). Nesse sentido, a irrigação é uma prática agrícola cujo propósito é manter adequado o status hídrico dos vegetais para assegurar o desenvolvimento, a produtividade e a rentabilidade econômica. Acrescente-se que durante o manejo da irrigação, o fornecimento de água otimizado de alta frequência condiciona o solo a manter-se com teor ótimo de umidade, favorecendo maior produtividade do meloeiro (SIQUEIRA et al., 2009) e da melancieira (LIMA JUNIOR; LOPES,
2009).

A respeito de algumas características fisiológicas observáveis em plantas submetidas a estresse, vários autores (KONRAD et al., 2005; CRUZ et al., 2009; MELO et al., 2010; SUASSUNA et al., 2010) têm analisado a fluorescência da clorofila a no estudo de mecanismos fotossintéticos em plantas condicionadas a estresse bióticos e abióticos como temperatura, radiação solar, deficiência hídrica, salinidade, presença de patógenos e herbicidas. Nesse contexto, o uso de parâmetros de fluorescência tem sido difundido, principalmente, no estudo de fotossíntese por ser um método que, além de nãodestrutivo, permite análise qualitativa e quantitativa da absorção e aproveitamento da energia luminosa por meio do fotossistema II e possíveis relações com a capacidade fotossintética (NETTO; CAMPOSTRINI; OLIVEIRA, 2005). Maxwell e Johnson (2000) contribuem acrescentando que o monitoramento das alterações na transferência de elétrons entre os fotossistemas do vegetal sob estresse pode ser avaliado em folhas intactas por meio da fluorescência da clorofila a. Por sua vez, Melo et al. (2010) mencionam que a melancieira externa valores reduzidos da eficiência fotoquímica sob déficit hídrico, indicando que esse parâmetro fisiológico pode ser utilizado como ferramenta no manejo da irrigação dessa olerícola.

Em relação às características de produção, os melões pertencentes ao grupo Cantalupensis são aromáticos, esféricos, intensa reticulação, polpa de coloração salmão e peso médio entre $700 \mathrm{~g}$ a 1.200 g (GOMES JÚNIOR et al., 2001; MEDEIROS et al., 2011). Das variáveis físico-químicas, um fator importante é o teor de sólidos solúveis totais (brix) que é utilizado como índice de classificação 
dos frutos de acordo com seu grau de doçura. Em alguns tipos de frutos, o brix é necessário tanto para o consumo in natura, como para o processamento industrial, visto que elevados teores implicam em menor adição de açúcares, menor tempo de evaporação da água, menor gasto de energia e maior rendimento do produto, resultando em maior economia no processamento (SILVA et al., 2003), e constitui-se em indicador do "adoçamento" em decorrência, principalmente, da sacarose (LONG et al., 2004).

Assim, objetivou-se com este trabalho, avaliar o efeito de lâminas de irrigação sobre a eficiência fotoquímica e o rendimento de frutos de meloeiro nas condições edafoclimáticas do semiárido paraibano.

\section{Material e Métodos}

O experimento foi realizado entre setembro e novembro de 2007, em condições de campo, no Setor de Fruticultura e Ecofisiologia Vegetal da Universidade Estadual da Paraíba - UEPB, localizado no município de Catolé do Rocha - PB, nas coordenadas $6^{\circ} 21^{\prime} \mathrm{S}$ de latitude, $37^{\circ} 48^{\prime}$ de longitude $\mathrm{O}$ e altitude de $250 \mathrm{~m}$.

O clima da região é do tipo BSw'h' segundo classificação de Köppen, caracterizando-se por ser semiárido quente, com duas estações distintas, uma chuvosa com precipitação irregular e outra sem precipitação. A precipitação pluviométrica média anual é de $870 \mathrm{~mm}$, temperatura média de $27^{\circ} \mathrm{C}$ com período chuvoso concentrando-se entre os meses de fevereiro e abril.

Foram avaliadas quatro lâminas de irrigação baseadas na evapotranspiração (ETo): 60, 80, 100 e $120 \%$ da ETo $\left(\mathrm{mm} \mathrm{dia}^{-1}\right)$, calculadas diariamente pela evaporação do Tanque classe A (TEODORO et al., 2004; AZEVEDO et al., 2005). As lâminas corresponderam aos volumes acumulados de água: $1250,1680,2110$ e $2540 \mathrm{~m}^{3}$ ciclo $^{-1}$, respectivamente. $\mathrm{O}$ delineamento experimental adotado foi o de blocos ao acaso com seis repetições e 10 plantas úteis por unidade experimental.

Antecipadamente ao plantio, as mudas da variedade 'Imperial', grupo Cantaloupe, foram produzidas em ambiente protegido, em recipientes contendo $0,05 \mathrm{~L}$ de substrato comercial à base de casca de Pinus e vermiculita. Transcorridos 20 dias da semeadura (DAS), as mudas foram transplantadas para o campo em solo previamente preparado por meio de gradagem e sulcamento, espaçadas de 2,2 $\mathrm{m}$ x 0,6 m em camalhões com altura média de 0,15 m. A adubação de fundação foi realizada no sulco de plantio, aplicando-se $10 \mathrm{~L}$ de esterco bovino e $0,1 \mathrm{~kg}$ de superfosfato simples por metro linear de extensão do sulco.

O solo local é classificado como NEOSSOLO FLÚVICO Eutrófico com textura arenosa, com as características químicas na camada de 0-20 $\mathrm{cm}$ foram as seguintes: cálcio $\left(5,51 \mathrm{cmol}_{\mathrm{c}} \mathrm{dm}^{-}\right.$ $\left.{ }^{3}\right)$; magnésio $\left(2,50 \mathrm{cmol}_{c} \mathrm{dm}^{-3}\right)$; sódio $\left(0,16 \mathrm{cmol}_{c}\right.$ $\left.\mathrm{dm}^{-3}\right)$; potássio $\left(0,89 \mathrm{cmol}_{\mathrm{c}} \mathrm{dm}^{-3}\right)$; hidrogênio $(0,00$ $\left.\mathrm{cmol}_{\mathrm{c}} \mathrm{dm}^{-3}\right)$; alumínio $\left(0,00 \mathrm{cmol}_{\mathrm{c}} \mathrm{dm}^{-3}\right)$; carbonato de cálcio qualitativo (presença); carbono crgânico (1,04 dag $\left.\mathrm{kg}^{-1}\right)$; matéria orgânica (1,79 dag $\mathrm{kg}^{-}$

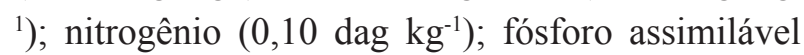
$(12,61 \mathrm{mg} / 100 \mathrm{~g}) ; \mathrm{pH} \mathrm{H}_{2} \mathrm{O}(1: 2,5)=7,57$; $\mathrm{CE}(0,35$ mmhos $\left.\mathrm{cm}^{-1}\right)$.

Utilizou-se um sistema de irrigação localizada por gotejamento, com emissores equidistantes de $0,6 \mathrm{~m}$ e vazão nominal de $2,1 \mathrm{~L} \mathrm{~h}^{-1}$. Baseandose na análise do solo e em recomendação de Crisóstomo et al. (2002), procederam-se as fertilizações de cobertura, realizadas semanalmente via fertirrigação. Para tanto, utilizou-se para injeção das soluções, o injetor tipo venturi calibrado para trabalhar na vazão de $70 \mathrm{~L} \mathrm{~h}^{-1}$.

Foram determinadas as fluorescências da clorofila $a$, no turno da manhã (9-10h) no período de floração plena (45 DAE) do meloeiro, utilizando-se um fluorômetro portátil (LI-1600, USA). As leituras foram realizadas nas folhas intermediárias dos ramos, pré-adaptadas ao escuro após período de 30 
minutos, de três plantas úteis por tratamentos e por repetição, registrando-se as fluorescências: inicial (Fo), máxima (Fm), variável (Fv) e Eficiência quântica do FSII (Fv/Fm) (SCHREIBER; BILGER; NEUBAUER, 1994).

Avaliou-se o rendimento dos frutos $(\mathrm{kg})$ seguindo a seguinte classificação com base em sua massa: classe I $>1 \mathrm{~kg}$; classe II de 0,8 a $1 \mathrm{~kg}$; e classe III $<0,8 \mathrm{~kg}$. Já a eficiência do uso da água foi obtida pela razão entre a produtividade quantificada em cada lâmina de irrigação e seus respectivos volumes totais de água utilizados durante o ciclo de produção da cultura (SOUSA et al., 2000).

Após a colheita dos frutos, foram analisadas as características físicas de diâmetro longitudinal e diâmetro transversal por meio da medição das circunferências do fruto, utilizando-se trena graduada em milímetro. $\mathrm{Na}$ ocasião, foram determinados os teores de sólidos solúveis totais (brix). As determinações do brix foram feitas imediatamente após a colheita, por meio do suco extraído de uma fatia do fruto de 0,05 $\mathrm{m}$ de largura macerada, utilizando o refratômetro digital manual (Modelo N- 50E).

Os dados coletados foram submetidos à análise de variância pelo teste $\mathrm{F}$, até $5 \%$ de significância, e os modelos de regressão ajustados conforme o coeficiente de regressão pelo teste t, até $5 \%$ de significância, por meio do programa SAEG 9.0.

\section{Resultados e Discussão}

A fluorescência inicial (Fo) do meloeiro foi influenciada pelas lâminas de irrigação, sendo explicada pelo modelo de regressão quadrático, encontrando-se valor máximo estimado $(310,72)$ no volume de água de $2400,62 \mathrm{~m}^{3}$ ciclo-1 $^{-1}$. Identificou-se aumento de $10,82 \%$ em relação ao menor volume $\left(1250 \mathrm{~m}^{3}\right.$ ciclo $\left.^{-1}\right)$, equivalente a $60 \%$ da ETo (Figura 1A). Saliente-se que a fluorescência inicial é definida como a intensidade de fluorescência quando todos os centros de reação do fotossistema II
(FSII) estão abertos e as membranas fotossintéticas desenergizadas e apresenta também um coeficiente de extinção fotoquímico (qp) igual a um e o não-fotoquímico (qnp) igual à zero (BAKER; ROSENQVST, 2004).

Ainda de acordo com Baker e Rosenqust (2004), o aumento em Fo revela destruição do centro de reação do PSII $\left(\mathrm{P}_{680}\right)$ ou diminuição na capacidade de transferência da energia de excitação da antena ao PSII. Os resultados encontrados neste trabalho revelaram aumento de Fo até a irrigação de 2400,62 $\mathrm{m}^{3}$ ciclo ${ }^{-1}$, sendo esta reduzida com o tratamento de $120 \%$ da ETo $\left(2540 \mathrm{~m}^{3}\right.$ ciclo $\left.^{-1}\right)$. Tal observação leva a crer que quando as plantas foram submetidas ao referido tratamento hídrico, as mesmas se encontravam com alguma perturbação no fotossistema II ocasionada pelas condições hídricas do solo.

Em relação ao comportamento da fluorescência máxima (Fm) (Figura 1B), vê-se que esta também se ajustou ao modelo quadrático em função das lâminas de irrigação, constatando-se a maior fluorescência $(1559,03)$ no volume de água estimado de 1954,23 $\mathrm{m}^{3}$ ciclo $^{-1}$. Esse comportamento correspondeu ao incremento de 9,38\%, ocorrido no intervalo entre $1250 \mathrm{~m}^{3}$ ciclo $^{-1}$ e a lâmina que promoveu o rendimento máximo (1954,23 $\mathrm{m}^{3}$ ciclo $\left.^{-1}\right)$. A diminuição de Fm caracteriza deficiência de fotorredução da quinona $A$ (QA), que pode estar associada à inativação do PSII nas membranas dos tilacóides, afetando diretamente o fluxo de elétrons entre os fotossistemas (SILVA et al., 2006). Sendo assim, esse evento ocorreu tanto em condições de deficiência hídrica, na menor lâmina, bem como em condições de alto suprimento hídrico (maior lâmina de irrigação).

O máximo estimado de Fm $(1792,23)$ em melancieira irrigada relatado por Melo et al. (2010) foi observado com irrigação baseada em $70 \%$ da ETo. No presente trabalho, o volume de água onde se identificou o ponto máximo, ficou próximo a $100 \%$ da ETo, evidenciando-se com isto, menor influência 
da água sobre este parâmetro de fluorescência da clorofila a no meloeiro. Notou-se, entretanto, semelhança no comportamento dessas olerícolas em relação a tal parâmetro. Conforme a literatura, a intensidade máxima de fluorescência (Fm) indica o estado em que os centros de reações do PSII são incapazes de aumentar as reações fotoquímicas e quando a fluorescência atinge sua capacidade máxima, denotando a condição reduzida de toda quinona (Qa) pelos elétrons transferidos a partir do PSII (BAKER; ROSENQVST, 2004).

Figura 1. Fluorescência inicial(Fo)(A), fluorescência máxima (B), fluorescência variável(C) e eficiência quântica do fotossistema II (D) do meloeiro Cantaloupe var. Imperial cultivado sob diferentes lâminas de irrigação.

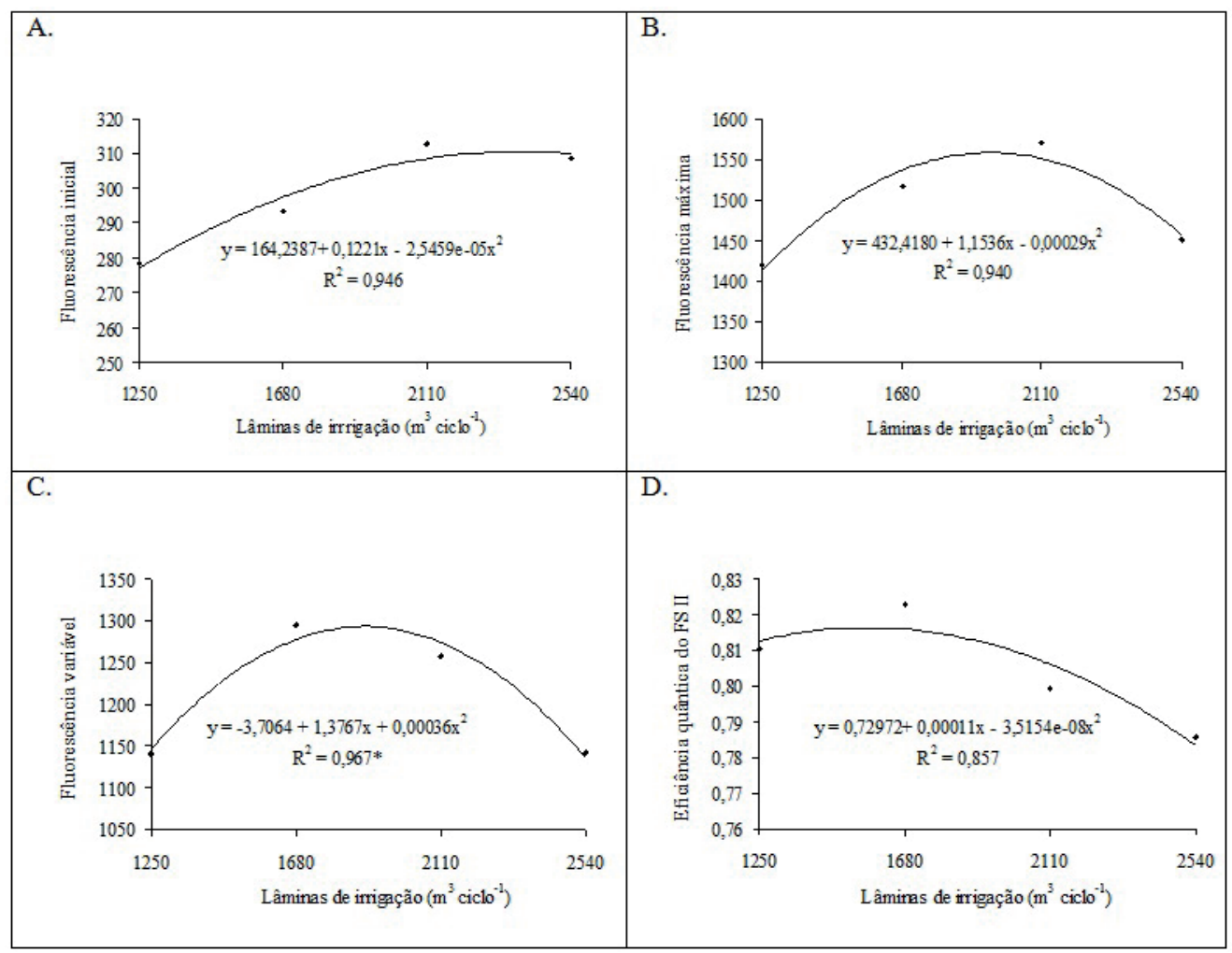

A característica de fluorescência variável (Fv) também se comportou quadraticamente nas lâminas de água (Figura 1C), sendo que a maior variação constatada foi de 1293,12 quando as plantas receberam $1830,56 \mathrm{~m}^{3}$ ciclo $^{-1}$ de água. Observa-se que houve acréscimo médio de $11,37 \%$ ocorrido no intervalo entre $1250 \mathrm{~m}^{3}$ ciclo $^{-1}$ e a lâmina máxima estimada de $1883,56 \mathrm{~m}^{3}$ ciclo-1 $^{-1}$. Após esse ponto, observouse redução de $12,11 \%$ até o maior volume de água $\left(2540 \mathrm{~m}^{3}\right.$ ciclo $\left.^{-1}\right)$. Esse resultado foi similar ao registrado por Melo et al. (2010), estudando níveis de irrigação na melancieira em condições edafoclimáticas semelhantes. Entretanto, esses autores constataram o valor máximo da fluorescência variável de 1427,04 nas lâminas de irrigação correspondentes a $70 \%$ da ETo; enquanto no presente estudo, tanto para Fo como para $\mathrm{Fv}$, o máximo estimado foi encontrado próximo à lâmina correspondente a $100 \%$ da ETo, sugerindo que o meloeiro é menos sensível em relação à condição de umidade do solo.

Com as plantas sob níveis variados de irrigação, a eficiência fotoquímica do Fotossistema II atingiu o máximo $(0,81)$ no volume estimado de $1600 \mathrm{~m}^{3}$ ciclo $^{-1}$ de água (Figura 1D). Ressalte- 
se que mesmo no tratamento de maior restrição hídrica, as plantas de meloeiro apresentaram eficiência fotoquímica acima do limite que poderia causar dano ao fotossistema II que é de 0,75 . Por sua vez, verificou-se que os níveis de água superiores a $1600 \mathrm{~m}^{3}$ ciclo $^{-1}$ provocaram redução em torno de $4,0 \%$ até o volume de 2540 $\mathrm{m}^{3}$ ciclo $^{-1}$ (120\% da ETo). Tal redução também foi observada por Melo et al. (2010) na cultura da melancia. Esses autores constataram reduções acentuadas da razão Fv/Fm quando adotou uma lâmina de irrigação equivalente $130 \%$ da ETo. Isso possivelmente indica inibição da atividade fotoquímica nas plantas, tal como ocorre também, nos menores níveis de irrigação, já que comumente, esta característica da fluorescência é usada como indicador de estresse, quando fatores bióticos ou abióticos alteram a funcionalidade do fotossistema II (DIAS; MARENCO, 2007).

É oportuno ressaltar que essa variável reflete a eficiência fotoquímica do FSII e tem sido utilizada na avaliação dos danos ao sistema fotossintético e a intensidade da fotoinibição pode ser avaliada pela redução deste parâmetro (DIAS; MARENCO, 2007). Em estudo sob estresse em citros (PEREIRA et al., 2000), em cultivares de cafeeiro (KONRAD et al., 2005), em melancieira (MELO et al., 2010) e em mudas de maracujazeiro (SUASSUNA et al., 2010), esses autores observaram decréscimos na razão $\mathrm{Fv} / \mathrm{Fm}$ como indicativo de efeito fotoinibitório nas plantas. Percebe-se dessa forma, que os vegetais sob algum tipo de estresse alteram seus mecanismos fisiológicos, os quais podem ser identificados por meio da análise da fluorescência da clorofila a antes que a planta venha a manifestar algum sintoma visual. Neste estudo, percebeu-se que tanto a lâmina de menor como a de maior disponibilidade hídrica (60 e 120\% da ETo) promoveram os menores valores absolutos dos parâmetros de fluorescência avaliados no meloeiro, reafirmando-se a influência desvantajosa da falta e do excesso de água no funcionamento do aparato fotossintético da planta.

$\mathrm{Na}$ Figura 2A estão dispostos os dados de produtividade do meloeiro ( $\mathrm{t} \mathrm{ha} \mathrm{h}^{-1}$ ), com ajuste significativo ao modelo linear crescente à medida que se aumentaram as lâminas de irrigação. A maior produtividade $\left(27,35 \mathrm{tha}^{-1}\right)$ foi registrada na aplicação de $2540 \mathrm{~m}^{3}$ de água durante o ciclo da cultura (120\% da ETo). Percebeu-se o maior aumento em produtividade $(9,10 \%)$ entre as lâminas de 2110 e $2540 \mathrm{~m}^{3}$ ciclo $^{-1}$. Semelhante aos valores de produtividade encontrados para esta variedade, Gomes Júnior et al. (2001) encontraram rendimentos médios de frutos que variaram de 15,81 a 24,37 $\mathrm{tha}^{-1}$.

Quanto à eficiência no uso da água (EUA) (Figura 2B), constatou-se decréscimo pelo aumento dos volumes de água usados na irrigação, com ajuste dos dados a um modelo de regressão exponencial. O menor valor de EUA $(0,01 \mathrm{t}$ $\mathrm{m}^{3}$ ) foi verificado no maior volume de água aplicado. Apesar da maior lâmina de irrigação ter promovido acréscimo na produtividade de $21,86 \%$ em relação ao menor nível de irrigação $(60 \%$ da ETo), houve redução de 41,17\% na EUA, com queda nos valores de $0,017 \mathrm{t} \mathrm{m}^{-3}$ para $0,01 \mathrm{t} \mathrm{m}^{-3}$. Isso evidencia que o aumento em produtividade foi pouco expressivo em relação à quantidade de água aumentada, reduzindo-se dessa forma a eficiência do uso deste insumo pelo meloeiro.

Em estudo com irrigação em meloeiro, Monteiro et al. (2008) verificaram que a EUA decresceu com o aumento da lâmina de irrigação, tendo em vista que a produtividade não aumentou em proporção ao fornecimento de água. A máxima EUA em melancieira irrigada foi identificada por Melo et al. (2010), manejando a irrigação baseada em 25\% da evaporação do Tanque Classe A. Para os últimos autores, isso foi devido ao pequeno decréscimo na produtividade, quando comparado à alta redução no uso da água. Já Monteiro et al. (2008) encontraram a maior EUA $\left(70,4 \mathrm{~kg} \mathrm{ha}^{-1}\right.$ $\mathrm{mm}^{-1}$ ) na lâmina de água de $232,7 \mathrm{~mm}$. 
Figura 2. Produtividade (A) e eficiência do uso da água (B) do meloeiro Cantaloupe var. Imperial cultivado sob diferentes lâminas de irrigação.

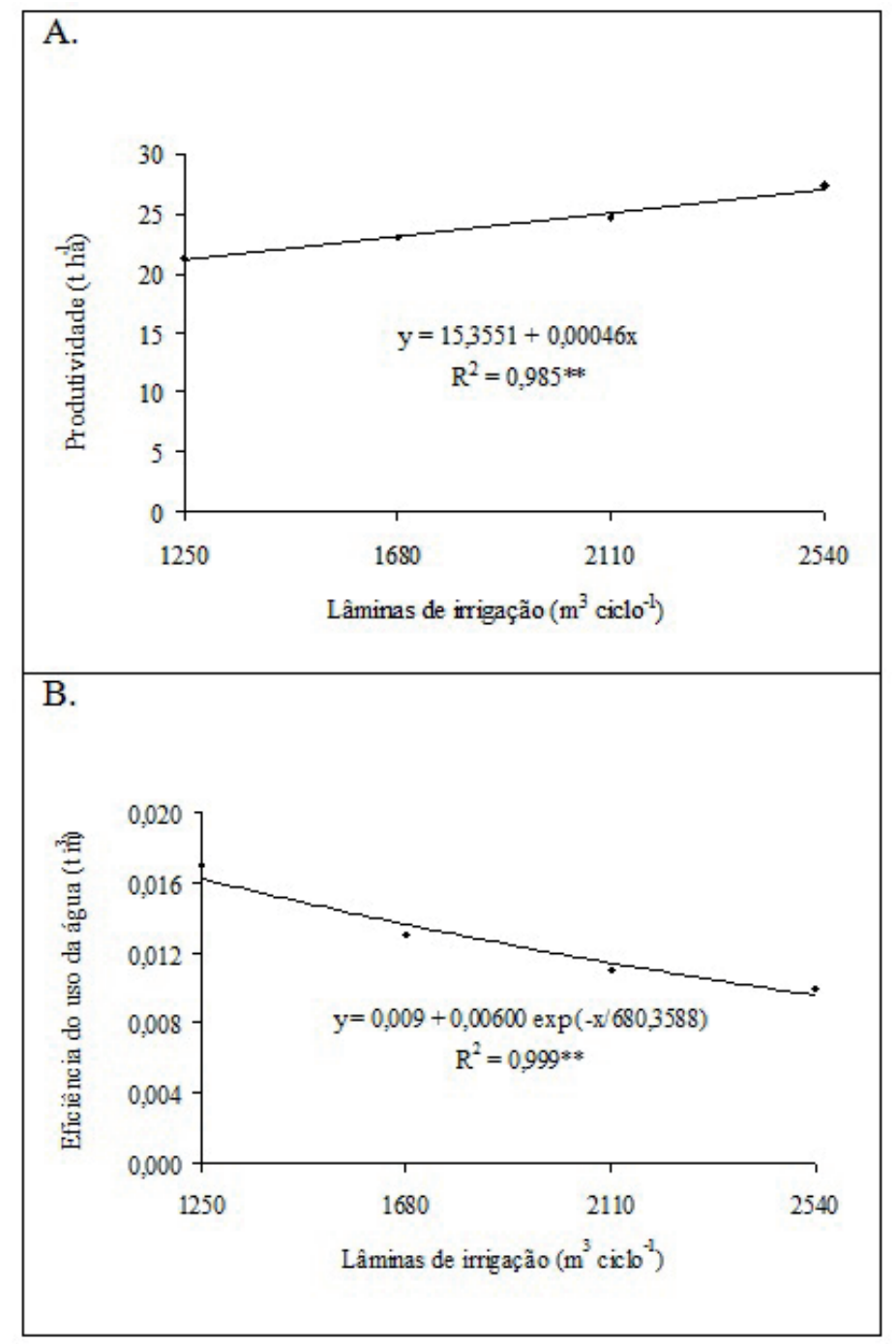

Quanto ao rendimento do meloeiro, os resultados deste componente de produção estão ilustrados na Figura 3, assim como a sua classificação com base na massa média dos frutos (classe $\mathrm{I}>1,0 \mathrm{~kg}$; classe II de 0,8 a $1,0 \mathrm{~kg}$ e classe III $<0,8 \mathrm{~kg}$ ). Os frutos classe I (Figura 3A) tiveram sua massa média representada por um modelo quadrático em função da disponibilidade de água. Após a constatação da massa máximo dos frutos de $1,17 \mathrm{~kg}$, verificou-se diminuição quando se passou a utilizar $2540 \mathrm{~m} 3$ de água na irrigação. Já a massa média dos frutos dentro da classe II (entre 0,8 e $1,0 \mathrm{~kg}$ ) (Figura 3B) aumentou linearmente em 4,39\% da menor (1250 $\mathrm{m}^{3}$ ciclo $^{-1}$ ) para a maior lâmina de água aplicada $\left(2540 \mathrm{~m}^{3}\right.$ ciclo $\left.^{-1}\right)$. Comportamento semelhante foi identificado para os frutos da classe III $(<0,8 \mathrm{~kg})$ (Figura 3C), onde se observa incremento de $4,68 \%$ nesse mesmo intervalo de irrigação. Este estudo confirma a importância do manejo correto da irrigação na padronização dos frutos, sobretudo os destinados à exportação (DANTAS; MEDEIROS; FREIRE, 2011). 
Figura 3. Rendimento de fruto na classe I ( $>1,0 \mathrm{~kg}$ ) (A), classe II (entre 0,8 e 1,0 kg) (B) e classe III $(<0,8$ $\mathrm{kg})(\mathrm{C})$ do meloeiro Cantaloupe var. Imperial cultivado sob diferentes lâminas de irrigação.

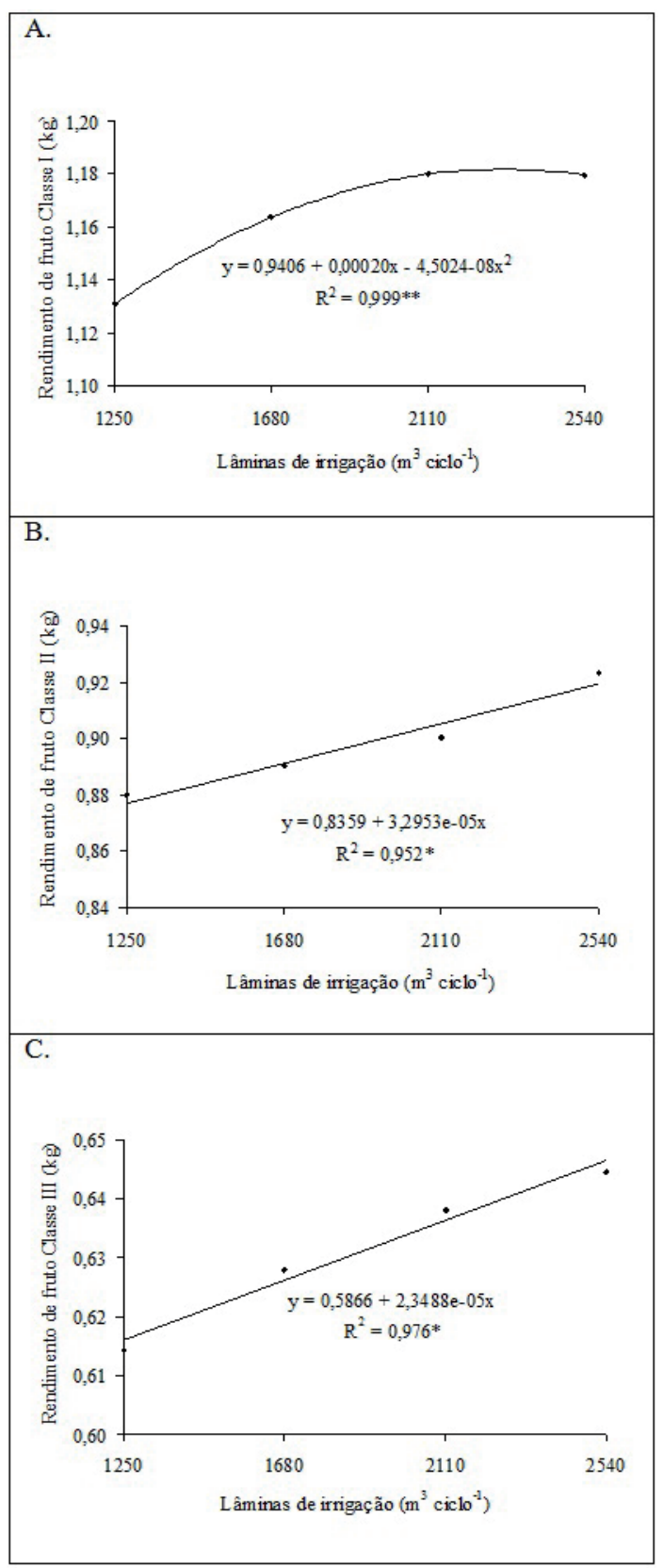

O maior rendimento é resultado do teor de água no solo mais adequado às plantas, o que permitiu melhoria na disponibilidade de nutrientes e, consequentemente, aumento da área foliar. Isso tende possibilitar acréscimo na produção de fotoassimilados e ganho em produtividade pelas plantas (TEODORO et al., 2004; SALDANHA, 2008). Para Saldanha (2008), maiores incrementos no rendimento de frutos comercializáveis de melão Cantaloupe ocorrem de forma linear em função do aumento das lâminas de irrigação. No que se refere ao tamanho dos frutos, Medeiros et al. (2011) acrescentam que as massas de frutos comerciais variam de 1,0 a $1,5 \mathrm{~kg}$ e que os frutos maiores, desvalorizados no mercado externo, são vendidos no mercado interno. 
Em relação às características físicas, os diâmetros longitudinal e transversal dos frutos (Figura 4), foram explicados por uma função quadrática em relação ao aumento da disponibilidade de água. $\mathrm{O}$ cultivo do meloeiro na lâmina máxima estimada de $2153,75 \mathrm{~m}^{3}$ ciclo $^{-1}$ resultou no valor máximo de diâmetro longitudinal dos frutos $(0,119 \mathrm{~m})$ (Figura 4A). Notou-se a mesma tendência para o diâmetro transversal dos frutos $(0,120 \mathrm{~m})$ (Figura 4B), quando se usou 2487,5 $\mathrm{m}^{3}$ ciclo-1 $^{-1}$. As lâminas de irrigação superiores a 100\% da ETo promoveram redução das variáveis físicas dos frutos de meloeiro Cantaloupe, interferindo negativamente sob as características qualitativas externas, visto que estas são as mais visadas pelo mercado consumidor.

A conformação do fruto, por influenciar sua aparência externa, é um atributo de qualidade. Saliente-se que as condições de cultivo inadequadas afetam diretamente as características relacionadas ao padrão de qualidade exigido pelo mercado consumidor (SALES JÚNIOR et al., 2006). A comercialização no mercado internacional exige a observação de critérios nutricionais, higiênicos e sensoriais que influenciam a aceitação pelo consumidor, além da resistência ao manuseio, transporte e armazenamento que determinam o preço do produto (MIRANDA et al., 2005).

O teor de sólidos solúveis totais (brix) no meloeiro submetido aos níveis de irrigação teve crescimento acentuado até a segunda lâmina aplicada, sendo obtido o valor máximo de 10,3 brix e aumento percentual de $19,74 \%$ em relação à menor lâmina de irrigação $\left(1250 \mathrm{~m}^{3}\right.$ ciclo $\left.^{-1}\right)$ (Figura 5). Essa característica constitui-se uma das variáveis mais importantes para se medir à qualidade do fruto do meloeiro. Seu conteúdo indica o seu amadurecimento e correlação positiva com o teor de açúcares e dá ideia da doçura da fruta, atributo sensorial mais importante para o consumidor.

Figura 4. Diâmetro longitudinal (A) e diâmetro transversal (B) de frutos do meloeiro Cantaloupe var. Imperial cultivado sob diferentes lâminas de irrigação.

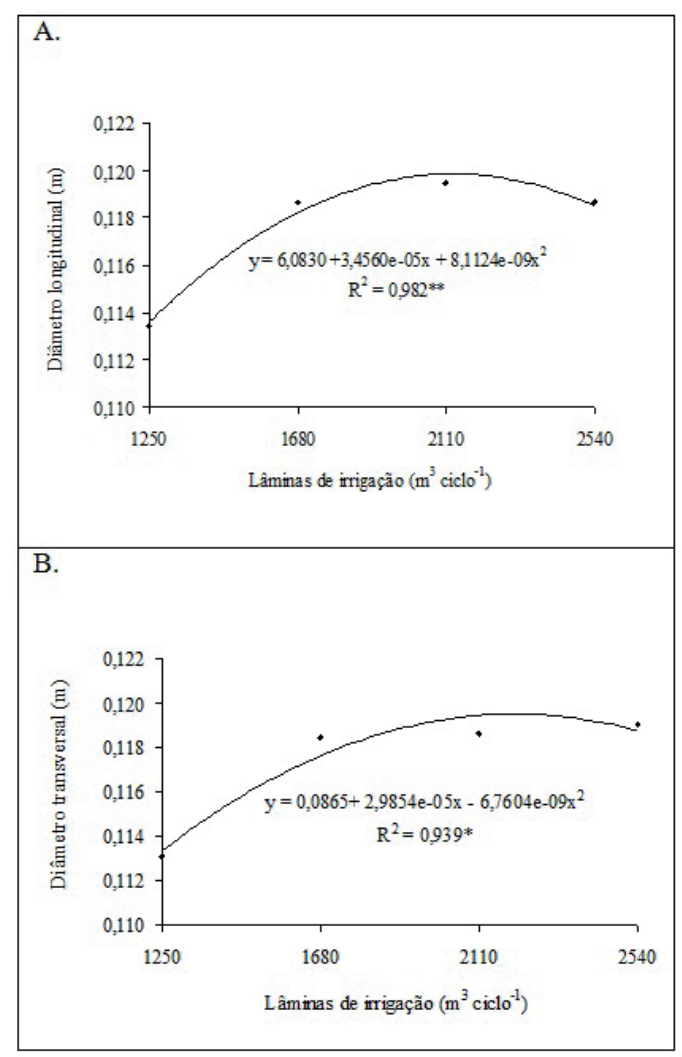


Figura 5. Teor de sólidos solúveis totais (brix) em frutos do meloeiro Cantaloupe var. Imperial cultivado sob diferentes lâminas de irrigação.

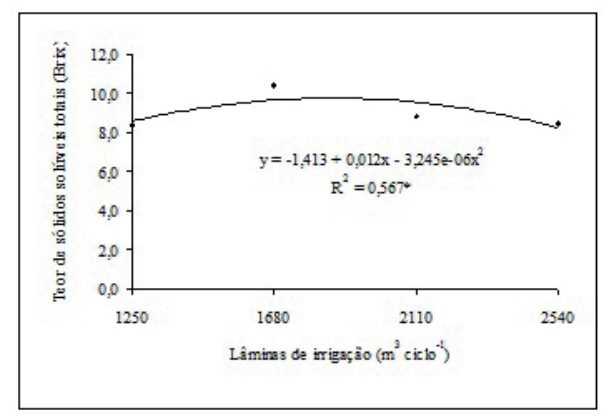

Segundo Sales Júnior et al. (2006), melões com menos de 9 brix são considerados não comercializáveis, porque esse atributo não aumenta após a colheita. Esses autores registraram em melão Cantaloupe, valor de 10 brix ao analisarem a qualidade de algumas variedades para exportação. Siqueira et al. (2009) acrescentam que o teor de sólidos solúveis totais pode ser influenciado por fatores genéticos, ambientais, irrigação e nutrição das plantas. Nesse caso, no presente trabalho, a deficiência e o excesso de água prejudicaram tal atributo, visto que a menor $\left(1250 \mathrm{~m}^{3}\right.$ ciclo- 1$) \mathrm{e}$ a maior (2540 $\mathrm{m}^{3}$ ciclo-1 $^{-1}$ lâminas de irrigação apresentaram valores indesejáveis ao comércio de frutos (8,33 e 8,48 de brix, respectivamente).

\section{Conclusões}

A eficiência fotoquímica do Fotossistema II no meloeiro aumentou com irrigação baseada em $80 \%$ da ET0 sem indicação de prejuízos ou danos ao Fotossistema II.

O aumento das lâminas de água promoveu maior produtividade, no entanto o tamanho do fruto, o teor de açúcar e a eficiência no uso da água foram reduzidos com uso de laminas acima de $100 \%$ da ETo.

Lâminas de irrigação baseadas em $100 \%$ da ETo, estimadas em $2110 \mathrm{~m}^{3}$ ciclo $^{-1}$, proporcionam os maiores índices para as variáveis de produção analisadas neste trabalho, considerando-se como parâmetros a produtividade total e qualidade dos frutos.

\section{Referências}

ANUÁRIO ESTATÍSTICO DA AGRICULTURA BRASILEIRA - AGRIANUAL. São Paulo: FNP Consultoria \& Agroinformática, 2009.

AZEVEDO, B. M.; BASTOS, F. G. C.; VIANA, T. V. A.; RÊGO, J. L.; D’ÁVILA, J. H. Efeitos de níveis de irrigação na cultura da melancia. Revista Ciência Agronômica, Fortaleza, v. 36, n. 1, p. 9-15, 2005.

BAKER, N. R.; ROSENQVST, E. Aplication of chlorophyll fluorescence can improve crop production strategies: an examination of future possibilities. Journal of Experimental Botany, Oxford, v. 55, n. 403, p. 16071621, 2004.

CRISÓSTOMO, L. A.; SANTOS, A. A. dos; RAIJ, B. V.; FARIA, C. M. B. de; SILVA, D. J. da; FERNANDES, F. A. M.; SANTOS, F. J. S. de; CRISÓSTOMO, J. R.; FREITAS, J. A. D. de; HOLANDA, J. S. de; COSTA, N. D. Adubação, irrigação, híbridos e práticas culturais para o meloeiro no Nordeste. Fortaleza: Embrapa Agroindústria Tropical. 2002. 21 p. (Circular técnica, 14).

CRUZ, M. do C. M.; SIQUEIRA, D. L.; SALOMÃO, L. C. C.; CECON, P. R. Fluorescência da clorofila a em folhas de tangerineira 'Ponkan' e limeira ácida 'Tahiti' submetidas ao estresse hídrico. Revista Brasileira de Fruticultura, Jaboticabal, v. 31, n. 3, p. 896-901, 2009.

DANTAS, D. C. da; MEDEIROS, J. F.; FREIRE, A. G. Produção e qualidade do meloeiro cultivado com filmes plásticos em respostas à lâmina de irrigação. Revista Ciência Agronômica, Fortaleza, v. 42, n. 3, p. 652-661, 2011.

DEMARTELAERE, A. C. F.; DUTRA, I.; ALVES, S. S. 
V.; TEÓFILO, T. M. da. S; ALVES, S. V. Utilização de polímero hidroabsorvente no meloeiro (Cucumis melo L.) sob diferentes lâminas de irrigação. Revista Caatinga, Mossoró, v. 22, n. 3, p. 05-08, 2009.

DIAS, D.P.; MARENCO, R.A. Fotossíntese e fotoinibição em mogno e acariquara em função da luminosidade e temperatura foliar. Pesquisa Agropecuária Brasileira, Brasília, v. 42, n. 3, p. 305-311, 2007.

DOGAN, E.; KIRNAK, E. H.; BEREKATOGLU, E. K.; BILGEL, E. L.; SURUCU, E. A. Water stress imposed on muskmelon (Cucumis melo L.) with subsurface and surface drip irrigation systems under semi-arid climatic conditions. Irrigation Science, New York, v. 26, n. 2, p. 131-138, 2008.

FERREIRA, G. de S.; TORRES, S. B.; COSTA, A. R. F. C. da. Germinação e desenvolvimento inicial de plântulas de meloeiro em diferentes níveis de salinidade da água de irrigação. Revista Caatinga, Mossoró, v. 20, n. 3, p. 181$185,2007$.

GOMES JÚNIOR, J.; MENEZES, J. B.; NUNES, G. H. S.; COSTA, F. B.; SOUZA, P. A. Qualidade pós-colheita do melão tipo Cantaloupe, colhido em dois estádios de maturação. Horticultura Brasileira, Brasília, v. 19, n. 3, p. 223-227, 2001.

INSTITUTO BRASILEIRO DE GEOGRAFIA E ESTATÍSTICA - IBGE. Produção agrícola municipal. Lavoura temporária melão. Produção e área plantada de melão, Brasil. 2010. Disponível em <http://www.sidra. ibge.gov.br>. Acesso em: 02 jun. 2011.

KOETZ, M.; COElHO, G.; CARVAlHO, J. A.; SOUZA, R. J.; SILVA, R. A. Produção do meloeiro em ambiente protegido irrigado com diferentes lâminas de água. Irriga, Botucatu, v. 11, n. 4, p. 500-506, 2006.

KONRAD, M. L. F.; SILVA, J. A. B.; FURLANI, P. R.; MACHADO, E. C. Trocas gasosas e fluorescência da clorofila em seis cultivares de cafeeiro sob estresse de alumínio. Bragantia, Campinas, v. 64, n. 3, p. 339-347, 2005.

LIMA JUNIOR, J. A.; LOPES, P. R. A. Avaliação da cobertura do solo e métodos de irrigação na produção da melancia. Semina: Ciências Agrárias, Londrina, v. 30, n. 2, p. 315-322, 2009.

LONG, R. L.; WALSH, K. B.; ROGERS, G.; MIDMORE, D. J. Source-sink manipulation to increase melon (Cucumis melo L.) fruit biomass and soluble sugar content. Australian Journal of Agricultural Research, Australia, v. 55, n. 12, p. 1241-1251, 2004.

MAXWELL, K.; JOHNSON, G. N. Chlorophyll fluorescence: a practical guide. Journal Experimental Botany, Oxford, v. 51, n. 345, p. 659-668, 2000.
MEDEIROS, D. C.; MEDEIROS, J. F.; FRANCISCO, A. L. P.; SOUZA, R. O. de; PAHLEVI, A. de S. Produção e qualidade de melão Cantaloupe cultivado com água de diferentes níveis de salinidade. Revista Caatinga, Mossoró, v. 24, n. 1, p. 92-98, 2011.

MELO, A. S.; SUASSUNA, J. F.; FERNANDES, P. D.; BRITO, M. E. B.; SUASSUNA, A. F.; AGUIAR NETTO, A. O. Crescimento vegetativo, resistência estomática, eficiência fotossintética e rendimento do fruto da melancieira em diferentes níveis de água. Acta Scientiarum Agronomy, Maringá, v. 32, n. 1, p. 73-79, 2010 .

MIRANDA, N. de O.; OLIVEIRA, T. S. de; LEVIEN, S. L. A.; SOUZA, E. R. de. Variabilidade espacial da qualidade de frutos de melão em áreas fertirrigadas. Horticultura Brasileira, Brasília, v. 23, n. 5, p. 242-249, 2005.

MONTEIRO, R. O. C.; COSTA, R. N. T.; LEÃO, M. C. S.; AGUIAR, J. V. Eficiência do uso da água e nitrogênio na produção de melão. Irriga, Botucatu, v. 13, n. 3, p. 367-377, 2008.

NETTO, A. T.; CAMPOSTRINI, E.; OLIVEIRA, G. J. Photosynthetic pigments, nitrogen, chlorophyll a fluorescence and SPAD-502 readings in coffee leaves. Scientia Horticulturae, Amsterdam, v. 104, n. 2, p. 199209, 2005.

PEREIRA, W. E.; SIQUEIRA, D. L.; MARTINEZ, C. A.; PUIATTI, M. Gas exchange and chlorophyll fluorescence in four citrus rootstocks under aluminium stress. Journal of Plant Physiology, Londrina, v. 157, n. 3, p. 513-520, 2000.

SALDANHA, T. R. F. C. Produção e qualidade de melão Cantaloupe cultivado sob condições de diferentes tipos de cobertura e lâminas de irrigação. 2008. Dissertação (Mestrado em Irrigação e Drenagem) - Universidade Federal Rural do Semiárido, Mossoró.

SALES JÚNIOR, R.; DANTAS, F. F.; SALVIANO, A. M.; NUNES. G. H. S. Qualidade do melão exportado pelo porto de Natal-RN. Ciência Rural, Santa Maria, v. 36, n. 1, p. 286-289, 2006.

SCHREIBER, V.; BILGER, W.; NEUBAUER, C. Chlorophyll fluorescence as a no intrusive indicator for rapid assessment of in vivo photosynthesis. In: SHULZE, E. D.; CALDWELL, M. M. (Ed.). Ecophysiology of photosynthesis. Verlag: Schulze and mm Caldwell, 1994, p. 49-70. (Ecological studies, 100).

SILVA, M. M. P. da; VASQUEZ, H. M.; BRESSANSMITH, R.; SILVA, J. F. C.; ERBESDOBLER, E. D.; ANDRADE JÚNIOR, P. S. C. Eficiência fotoquímica de gramíneas forrageiras tropicais submetidas à deficiência 
hídrica. Revista Brasileira de Zootecnia, Viçosa, v. 35, n. 1, p. 67-74, 2006.

SILVA, P. S.; MENEZES, J. B.; OLIVEIRA, O. F.; SILVA, P. I. B. Distribuição do teor de sólidos solúveis totais no melão. Horticultura Brasileira, Brasília, v. 21, n. 1, p. 31-33, 2003.

SIQUEIRA, W. C.; FARIA, L. A.; LIMA, E. M. C.; REZENDE, F. C.; GOMES, L. A. A.; CUSTÓDIO, T. N. Qualidade de frutos de melão amarelo cultivado em casa de vegetação sob diferentes lâminas de irrigação. Ciência e Agrotecnologia, Lavras, v. 33, n. 4, p. 1041-1046, 2009.

SOUSA, A. E. C.; BEZERRA F. M. L.; SOUSA, C. H. de; SANTOS, F. S. S. dos. Produtividade do meloeiro sob lâmina de irrigação e adubação potássica. Engenharia Agricola, Jaboticabal, v. 30, n. 2, p. 271-278, 2010.

SOUSA, V. F. de; COÊLHO, E. F.; FIZZONE, J. A.; FOLEGATTI, M. V.; ANDRADE JÚNIOR, A. S.; OLIVEIRA, F. das C. Eficiência do uso da água pelo meloeiro sob diferentes freqüências de irrigação. Revista Brasileira de Engenharia Agrícola e Ambiental, Campina Grande, v. 4, n. 2, p. 183-188, 2000.

SUASSUNA, J. F.; MELO, A. S.; SOUSA, M. S. da S.; COSTA, F. da S.; FERNANDES, P. D.; PEREIRA, V. M.; BRITO, M. E. B. Desenvolvimento e eficiência fotoquímica em mudas de híbrido de maracujazeiro sob lâminas de água. Bioscience Journal, Uberlândia, v. 26, n. 4, p. 566-571, 2010.

TEODORO, R. E. F.; ALMEIDA, F. P.; LUZ, J. M. Q.; MELO, B. Diferentes lâminas de irrigação por gotejamento na cultura de melancia (Citrullus lanatus). Bioscience Journal, Uberlândia, v. 20, n. 1, p. 29-32, 2004. 